\title{
ESPAÇO PUBLIDIÁTICO E HEGEMONIA IDEOLÓGICA CONSTRUÇÃO NARRATIVA ATRAVESSADA PELO IMAGINÁRIO
}

\author{
ESPACIO PUBLIDIÁTICO Y HEGEMONÍA IDEOLÓGICA: CONSTRUCCIÓN \\ NARRATIVA ATRAVESADA POR EL IMAGINARIO
}

\begin{abstract}
PUBLIC AND MEDIA SPACE AND IDEOLOGICAL HEGEMONY A NARRATIVE CONSTRUCTION CROSSED BY THE IMAGINARY
\end{abstract}

\author{
ESPACE PUBLIMÉDIATIQUE ET HÉGÉMONIE IDÉOLOGIQUE \\ CONSCTRUCTION NARRATIVE TRAVERSÉE PAR L'IMAGINAIRE
}

DOI: $10.5533 / 1984-2503-20102407$

\section{Wilson Couto Borges}

\section{RESUMO}

Com este trabalho, buscamos apresentar algumas das principais reflexões desenvolvidas em nossa tese de doutorado sobre a relação entre as narrativas produzidas pelos meios de informação, o imaginário social e a ideologia. Para tanto, partiremos de um caso concreto presente na mídia apontando suas conexões com práticas distantes no tempo e no espaço, através da noção de inconsciente político do autor, destacando o quanto impressões, emoções, sensações, sentidos particulares são universalizados pelos "homens de imprensa".

Palavras-chave: Ideologia, Imaginário, Jornalismo, Narrativa, Inconsciente Político.

\section{RESUMEN}

En este trabajo, objetivamos presentar algunas de las principales reflexiones desarrolladas en nuestra tesis doctoral sobre la relación entre las narrativas producidas por los medios de información, el imaginario social y la ideología. Para ello, partiremos de un caso concreto presente en la midia apuntando sus conexiones con prácticas distantes en el tiempo y en el espacio, a través de la noción de 
inconsciente político del autor, destacándose lo cuanto impresiones, sensaciones, sentidos particulares son universalizados por los "hombres de la prensa".

Palabras-clave: Ideología, imaginario, periodismo, narrativa, incosciente político.

\section{ABSTRACT}

This work presents some of the main reflections, developed in our doctoral dissertation, on the relationship between the narratives produced by the means of information, social imaginary and ideology. To do so, it resorts to a concrete case present in the media. After pointing out its connections to practices distant in time and space, through the notion of political unconscious of the author, it highlights to what extent particular impressions, emotions, sensations and meanings are universalized by the 'men of the press'.

Key words: Ideology, imaginary, journalism, narrative, political unconscious.

\section{RÉSUMÉ}

Avec ce travail, nous prétendons présenter certaines des principales réflexions développées dans notre thèse de doctorat concernant les rapports existants entre les récits produits par les moyens d'information, l'imaginaire social et l'idéologie. À cet effet, nous partirons d'un cas concret issu des médias pour signaler ses connexions avec des pratiques éloignées dans le temps et dans l'espace, grâce à la notion d'inconscient politique de l'auteur. Nous mettrons en outre l'accent sur la façon dont des impressions, des émotions, des sensations et des significations particulières sont universalisées par les « hommes de presse ".

Mots-clés : Idéologie, imaginaire, journalisme, récit, inconscient politique.

Nos dias 4 e 5 de março deste ano, tivemos a oportunidade de acompanhar pelos meios de informação um episódio que, se não chamava a atenção pela notícia em si, destacava-se pelo conjunto dos depoimentos que o cercavam. Tratou-se daquilo que as fontes oficiais (dentre outras, a Secretaria Estadual de Segurança Pública) classificaram como "surto psicótico" de um agente da Polícia Civil. De todas as falas concorrentes, uma em especial vai nos interessar aqui: a de um repórter da Rádio Tupi, que acompanhou durante horas o desenrolar dos acontecimentos. 
Antes, porém, vamos à sequência dos fatos. De acordo com a dinâmica descrita pelos veículos, ao receber a escala de serviço, um policial foi à sala de seu superior - o delegado responsável -, iniciando uma acalorada discussão, que culminou com o agente sacando sua arma e ameaçando matar o titular de 39a DP (Pavuna). Ao presenciar aquela cena que poderia acabar de forma trágica, um inspetor (apontado como um dos mais qualificados negociadores daquela instituição policial) conseguiu retirar o titular da delegacia, permanecendo ele mesmo por aproximadamente cinco horas ponderando com seu colega de profissão. Ao final, para alívio dos personagens envolvidos, o protagonista entregou sua arma, rendendo-se em seguida.

Há uma longa discussão, que não convém ser aprofundada aqui, sobre o papel desempenhado pelos três principais meios de difusão da notícia: rádio, TV e impresso. Mas, em linhas gerais, ao primeiro, pela facilidade na mobilidade, caberia a função de trazer a notícia em primeira mão, afinal, para tanto, basta que um repórter tenha um telefone celular e do local transmita os acontecimentos "em tempo real" aos ouvintes; ao segundo, através da convergência entre imagem e som, utilizar do poder que a imagem em movimento goza para produzir um estatuto de verdade junto aos telespectadores, especialmente em função do prestígio que a máxima "uma imagem vale mais que mil palavras" desfruta no imaginário social; ao último, sobretudo por, em geral, circular apenas no dia seguinte ao fato, contextualizar um pouco mais a notícia para os leitores, isto porque como as informações nos outros dois são muito sintéticas (o custo é medido por tempo) os jornais impressos produzem a sensação de que a apuração foi muito além daqueles. Isto posto, ficaremos com o conjunto das narrativas produzidas pela rádio (neste caso, a Tupi) devido a imediatez da cobertura e pela proximidade com os ouvintes.

Durante a programação do chamado "Show do Apolinho" foram várias as inserções que o repórter realizou para atualizar aos ouvintes sobre aquele conflito que, em suas palavras, "poderia acabar numa tragédia". Menos nos interessa o episódio em si, seja numa dimensão sociológica seja humana, tampouco o estamos valorando. Mas, ele se revela um interessante caso analítico na justa medida em que se insere no antagonismo social brasileiro, não no embate entre chefe e subordinado, mas revelado através da oposição "pessoas de bem" versus "criminoso". 
Expliquemos melhor: numa das participações do personagem que fazia a cobertura daquele conflito, a apresentador do "Show" o interpela: "mas, vem cá, se o delegado já saiu e o problema do rapaz era com ele, por que essa situação continua se arrastando?' Resposta do repórter: "Na verdade, o clima está tenso. O rapaz continua armado e ameaçando atirar. O negociador está lá dentro, mas não pode tomar a arma da mão dele". O apresentador o interrompe e pergunta: "o cara estava dizendo que iria matar o delegado, mas se ele não está mais lá, é só entrar e prender o rapaz". O repórter retoma a fala e argumenta: "infelizmente não é assim. Trata-se de um trabalhador que deve ter algum problema psicológico. Os atiradores de elite já estão até posicionados. A situação é bem tensa. Se fosse um marginal ficava mais fácil, era só dar um tiro na cabeça e acabava a história". Pois bem, num só golpe, o intrépido homem de imprensa atualizava não só nosso antagonismo social, mas o fazia inclusive com relação à pena de morte para aqueles que, se não são culpados legalmente, o são moralmente.

O que a passagem do parágrafo anterior guarda de singular é a amplificação de uma determinada forma de pensar junto a uma audiência que, pelos números, é de relativa expressão. Neste caso, nos vemos diante daquele movimento que Jameson, White, Stallybrass, Cerqueira Filho, Zizek e nós enxergamos como a manifestação do inconsciente político do autor. Isto é, a abordagem daquele profissional do rádio estava atravessada, ainda que o próprio eventualmente não tenha consciência disso, por um processo onde o imaginário social aparece numa perspectiva conservadora e é construído na longa duração.

$\mathrm{Na}$ verdade, longe de representar um processo de mediação entre aquilo que efetivamente ocorreu e a recepção, nossa proposta teórica trabalha com as construções narrativas produzidas pelos veículos de comunicação no marco daquilo que afirmamos ser um novo tipo de espaço público: o espaço publidiático. Isto é, se em outros momentos da nossa história a imprensa era concebida como um dos aparelhos privados da sociedade civil, contemporaneamente, na exata medida em que produz um amálgama de vários discursos dentro dela, ela tende a se converter num simulacro da sociedade civil, ou como preferimos no espaço publidiático. Sendo nossa premissa pertinente, as informações trazidas pelo repórter da Rádio Tupi reificam no imaginário social a noção de que a execução de um "criminoso" é legitima (ainda que seja ilegal). 
Há aqui duas construções ideológicas que se tocam e se complementam além de se fossilizarem no tempo: a primeira é a de que o jornalista é um portador da verdade, trabalho que realiza de maneira imparcial, neutra, objetiva, atualizando alguns dos princípios celebrados pelo jornalismo norte-americano, que encontra na imprensa brasileira um solo fértil para tal concepção, especialmente a partir dos anos 1950-60; a segunda, a de que a imprensa é um poder mediador, mas que se converte fantasisticamente num poder moderador, que é capaz de produzir sentenças sociais à medida que representa os interesses da sociedade. Evidentemente, o ponto de partida dessas produções é a noção de que os meios de informação refletem as demandas da sociedade. No entanto, queremos chamar a atenção para um aspecto bastante singular e que se configura neste artigo como linha para uma futura investigação. Trata-se da revisão da concepção da imprensa como veículo de publicização encontrada em Habermas ${ }^{1}$, ainda que este autor destaque as transformações sofridas pela atividade jornalística.

\section{II}

Dentro da abordagem teórico-metodológica que estamos propondo, encontramos em Gilbert Keith Chesterton um interessante ponto de ancoragem. Destacado escritor e crítico inglês, não podemos esquecer que Chesterton também desempenhou a atividade jornalística - sendo apontado inclusive como um locutor de rádio muito popular -, o que nos autoriza a tomar por empréstimo algumas de suas histórias sobre o padre-detetive Father Brown². Em A cabeleira roxa, Chesterton 3 conta o episódio em que o Padre Brown investiga um dos mitos que envolvem a aristocracia inglesa, neste caso o dos Eyres de Exmoor. Não trata-se aqui de um mero detalhe 0 fato de o relato envolver a pauta, a apuração, a elaboração da notícia, mas principalmente, a troca de correspondências entre o

\footnotetext{
${ }^{1}$ Habermas, Jürgen (1984). Mudança estrutural da esfera pública, Rio de Janeiro: Tempo Brasileiro.

2 Ainda que não seja o objeto principal da nossa argumentação, é um dado bastante interessante e revelador o fato de o protagonista das histórias de Chesterton ser Father Brown (Pai Brown). A opção por Padre Brown (Priest Brown) pode guardar relação com a influência de São Tomás de Aquino, cuja vida foi escrita pelo literato-jornalista inglês.

3 Chesterton, G. K. (2004). "A cabeleira roxa". In: Braga, R. (Coord.). Contos ingleses, Rio de Janeiro: Ediouro.
} 
repórter que cobria o caso e o redator-chefe do Daily Reformer - periódico escolhido pelo escritor para ser o pano de fundo do conto.

$\mathrm{Na}$ construção da personagem Edward Nutt (redator-chefe), assim o caracteriza Chesterton:

"o Sr. Nutt, bem como muitos que exercem funções de mando no jornalismo, poder-se-ia dizer, realmente, que sua emoção mais habitual fosse a de medo permanente: de processos de difamação, de perder anunciantes, de erros tipográficos, do olho-da-rua"4.

Note-se que um dos pontos mais interessantes das atividades do Sr. Nutt é o processo de revisão, com as constantes "substituições de palavras" como "adultério" por 'mau comportamento' ou 'judeu' por 'estrangeiro"'5, "sobrenatural' por 'maravilhosos', 'dar cabo', por 'reprimir"6 ou ainda "Deus' por 'circunstâncias"”. Por outro lado, o repórter Francis Finn era o responsável por abastecer o periódico com história sobre "feitiçaria e assombrações", isto é, aquilo que se presumia ser o principal interesse do leitor do Daily Reformer. Atravessando a construção narrativa de Chesterton, não menos significativa para nós é a presença da "autonomia do repórter" para cobrir o episódio, o que nos permite inferir sobre a presença das noções de imparcialidade, neutralidade, objetividade, no jornalismo inglês do século XIX.

No processo de construção da história do jornalismo brasileiro encontram-se duas poderosas influências ao longo desses 200 anos. Desde a vinda da Família Real para o Brasil (1808) até o início dos anos 1920, a principal influência era a francesa, com um tipo de jornalismo mais literário, romanceado, com narrativas onde se privilegiava a riqueza de detalhes. A partir desse momento, gradativamente, passaríamos a uma revisão desse modelo, especialmente em função da importação de alguns parâmetros do jornalismo norte-americano, o que produzirá, a partir das reformas gráficas e editoriais dos anos 1950-60, a hegemonia de um fazer jornalístico assentado nas concepções de lide, de pirâmide invertida, bem como de objetividade, neutralidade, imparcialidade. Note-se que, se entre em 1808 e 1821 fala-se da presença do jornalismo inglês, particularmente representado no Correio

\footnotetext{
4 Ibidem, p. 293-294.

5 Ibidem, p. 294.

6 Ibidem, p. 296.

7 Ibidem, p. 308.
} 
Braziliense, editado em Londres por Hipólito da Costa, a partir da nossa independência (1822), arrefece-se a necessidade de combater aquele jornal considerado clandestino.

Na verdade, ainda que o "jornalismo inglês" tenha desaparecido dos debates públicos, nos interrogamos se a mesma "erradicação" se produziu na prática e no imaginário dos homens de imprensa. Paralelamente, um dos grandes colaboradores de Chesterton no diário por ele editado (G.K.'s Weekly) foi Hebert Georg Wells. Sabe-se que H. G. Wells representou uma importante influência no jornalismo norteamericano, especialmente quando nos lembramos da reprodução de seu livro Guerra dos mundos narrado por Orson Wells e que levou aquela sociedade a um pânico generalizado.

Novamente, podemos notar a influência do "jornalismo inglês" no tipo de produção noticiosa elaborada na terra do Tio Sam. Seria factível pensarmos então que, seja atravessando o Atlântico seja descendo as Américas, práticas jornalísticas distantes no tempo e no espaço poderiam influenciar o tipo de imprensa que atualmente temos no Brasil? Seria possível estabelecermos analogias entre o Daily Reformer de Chesterton e os nossos diários reformados dos anos 1990? Seria ainda possível enxergarmos tal conexão a partir do relato elaborado pelo repórter Finn, que afirmava que sua descoberta jornalística e sua redação "hão de se ler por toda a Europa e, com certeza, por toda a América e todas as Colônias"8? Voltemos então ao $A$ cabeleira roxa.

Além da presença de uma narrativa que apelava às sensações (prática corrente no jornalismo inclusive nos dias atuais), "com subtítulos; e estes eram de sabor mais picante"9, Chesterton nos permite perceber o quanto a necessidade de se organizar os acontecimentos por ordem de importância (pirâmide invertida) já é uma prática corrente no jornalismo inglês na passagem do século XIX para $\circ \mathrm{XX}$, como mostra em outra passagem descrita por Finn: "sei que é de praxe entre os jornalistas apresentar o fim de uma reportagem no começo da mesma, antecipação a que denominam manchette"10. Não menos interessante é o recurso à sua imaginação (do repórter Finn) para dar conta da montagem dos estereótipos dos personagens de sua investigação: um padreco (o Padre Brown), um fidalgo (um

\footnotetext{
8 Ibidem, p. 303.

9 Ibidem, p. 296.

10 Ibidem.
} 
Eyres). No entanto, a validade de suas impressões (poderíamos mesmo dizer, do seu imaginário) se assenta no fato de arrogar-se:

\begin{abstract}
"Repórter calejado que sou, não me foi preciso forçar muito o meu descaramento para ir-me sentando logo junto à comprida mesa (...). O homenzarrão de preto tinha jeito de ser pessoa muito instruída e versada mormente nas antiguidades locais; o homenzinho, também de preto, embora muito menos falador, surpreendeu-me com sua ainda mais vasta cultura. De modo que nos entendemos e acomodamos muito bem"11.
\end{abstract}

Toda essa experiência do repórter Finn permite a ele antever que, no contexto da sua apuração, das suas investigações, "algumas das suas narrações não são próprias para o jornal"12. Na verdade, previamente a "dinastia dos Eyres" já era tratada como culpada de produzir os horrores materializados no personagem da cabeleira roxa. Nesse sentido, nos sentimos autorizados a propor que implicitamente outra analogia se faz presente, na exata medida em que, tanto lá quanto cá, os antecipadamente culpados tendem a não verem reproduzidas nas páginas dos periódicos suas demandas (suas narrações).

Evidentemente, Finn é apenas um primeiro "filtro" dos assuntos tratados pelo Daily Reformer. Ou seja, há nele uma construção imaginária do que deve (ou que não deve), do que pode (ou do que não pode), do que interessa (ou do que não interessa) ao diário, pois mesmo apurando e confirmando os fatos por ele investigados, com consulta a fontes de informação - "penso dever ao Dr. Mull a justiça de declarar que as minhas duas investigações iniciais confirmam a sua história"13 - sentencia em sua correspondência à redação: "Bom, digam vocês, aí no jornal, o que quiserem de tudo isso; ou tirem-Ihe o sentido que preferirem"14.

Evidentemente, as aproximações por nós propostas podem ser questionadas. No entanto, nos parece plausível pensar na atuação do repórter e do diário na perspectiva que aqui marcamos, isto é, na investigação do papel da imprensa como poderoso agente político. Mudou-se o conteúdo da construção - ontem, na Inglaterra, o combate à aristocracia; hoje, no Brasil, o combate às "classes perigosas" - sem que a forma sofresse profundas transformações. Quando o

\footnotetext{
11 Ibidem, p. 298.

12 Ibidem, p. 302.

13 Ibidem.

14 Ibidem.
} 
redator-chefe do Daily Reformer escreve ao repórter dizendo: "Sua reportagem serve, mas tenho que incluir-Ihe algumas manchettes; e nossos leitores jamais tolerariam uma personagem padre católico"15, vemos aqui a presença da noção de Contrato de Leitura, proposta por Véron ${ }^{16}$ e produzida a partir da construção teórica de Chartier ${ }^{17}$ sobre os Protocolos de Leitura ${ }^{18}$.

Não vamos estabelecer neste artigo uma profunda discussão sobre a presença de analogias no plano do conteúdo. Porém, quando nos deparamos com um relato (poderiam argumentar, simplesmente ficcional) como o que o repórter faz nas linhas finais de sua correspondência à redação - "Isto tudo me parece muito caracteristicamente adequado a incidir sob a nossa campanha contra a nossa aristocracia pelo que ela vale, e pelo que valerá ainda, enquanto Deus não nos mandar melhor gente"19 -, julgamos que estamos diante do mesmo processo descrito por Sevcenko20 sobre a primeira década do século XX, bem como o da última década, descrita por nós ${ }^{21}$.

\section{III}

As conexões entre aquilo que descrevem Chesterton, Sevcenko e Borges são particularmente importantes porque enxergamos nelas profundas semelhanças do ponto de vista da presença de construções narrativas que apelam às emoções, aos afetos, aos sentimentos, às sensações, imersas num processo mais amplo de difusão da ideologia dominante. Com essa perspectiva, nossas premissas apontam

\footnotetext{
15 Ibidem.

16 Véron, Eliseo (1981). A produção de sentido, São Paulo: Cultrix.

17 Chartier, Roger (1996). Práticas de leitura, São Paulo: Estação Liberdade.

18 Para Chartier, os Protocolos de Leitura representam "senhas, explicitas ou implícitas, que um autor inscreve em sua obra a fim de produzir uma leitura correta dela, ou seja, aquela que estará de acordo com sua intenção. Essas instruções, dirigidas claramente ou impostas inconscientemente ao leitor, visam definir o que deve ser uma relação correta com o texto e impor seu sentido" (lbidem, p. 95). Nossa opção em trabalhar com a noção de Protocolos de Leitura em detrimento da de Contrato de Leitura se dá em função de o direcionamento não ser produzido sempre de forma consciente.

19 Chesterton, G. K. (2004). Op. Cit., p. 307.

20 Sevcenko, Nicolau (1989). Literatura como missão: tensões sociais e criação cultural na Primeira República, São Paulo: Brasiliense.

21 Borges, Wilson Couto (2009). Narrativas jornalísticas como produção material da cultura: a presença do imaginário na construção ideológica em torno da criminalidade, Niterói: Tese de Doutorado em Comunicação, UFF.
} 
para a centralidade do imaginário como uma instância que orienta a produção cultural, evidenciando o processo pelo qual uma dada ideologia ganha o conjunto da sociedade, mormente pelo papel desempenhado pelos meios de comunicação de massa que, longe de simples difusores, tornam-se protagonistas na cristalização de determinadas representações de mundo. Com esta afirmação não queremos recuperar uma tradição teórica que concebia os receptores (fossem eles leitores, ouvintes ou telespectadores) como sujeitos passivos, que simplesmente consumiam e reproduziam as informações massivas. Entretanto, cremos que também não podemos negar que os Protocolos de Leitura representam uma porta aberta para compreendermos como um determinado saber é compartilhado por uma dada formação social.

Em nossa avaliação, os veículos de informação constroem, a partir de determinados mecanismos de produção das narrativas, uma aproximação entre a experiência humana e a contada nas páginas dos periódicos - ou seja, entre a realidade e a ficcionalidade. Desse modo, é muito interessante observar como o apelo às sensações e aos sentimentos tem sido uma importantíssima estratégia de interlocução entre os meios e a sociedade, o que evidencia a permanência dessas chaves-de-leitura (mais ou menos homogêneas) entre a narrativa jornalística e a sua leitura - pelos menos no intervalo entre os séculos XIX e XXI, sem perdermos de vista que tal narrativa se assenta sobre a verossimilhança.

Portanto, a narrativa jornalística é concebida para que o leitor empregue 0 sentido sobre ela, sendo os protocolos responsáveis por fornecerem as chaves para que tais sentidos sejam empregados de forma mais ou menos semelhantes. Assim, a forma como o antagonismo social vem sendo absorvido (a partir de um jogo tenso entre o que deve ser memorizado e o que deve ser esquecido) tem ainda produzido seus efeitos na conformação da sociedade brasileira.

Como nossa reflexão se desenvolve no sentido de apontar que o antagonismo social, ou a luta de classes, como nomeou Marx, está presente não no campo estrito da política, mas no da cultura - entendendo-o não só como arena de disputas e conflitos, mas também como espaço de mediação e de hibridização, de produção de sentidos e de significados - é fundamental que compreendamos que essa busca por produzir sentidos revela em si mesmo uma disputa por produzir memória, identidade e projetos. Com isso, o que buscamos apontar é o caráter processual (sempre circular) da dinâmica cultural, não perdendo de vista o jogo 
complexo que existe entre conter e resistir, entre negação e sedução entre os grupos sociais. Na verdade, o que estamos querendo é fugir da dicotomia simplificadora entre cultura popular versus cultura erudita, o que acabaria implicando num reducionismo que inviabilizaria a identificação das ambiguidades, as contradições, mas igualmente as permanências presentes nesse processo.

Em Chartier22, por exemplo, observa-se que desde o século XVI os textos e os livros eram destinados a uma civilidade, ocupando o impresso um papel significativo na circulação dos modelos culturais. Porém, e sem que qualquer anacronismo atravesse suas reflexões, o autor destaca que a apropriação dos conteúdos dos escritos se dava por mecanismos outros que não somente a leitura individualizada. Também não estamos menosprezando o fato de que uma parte considerável dos impressos (talvez a maioria) era consumida pelos clérigos, nobres ou letrados. O que nos interessa identificar são as formas como os leitores populares se apropriavam deste tipo de literatura, como é o caso descrito pelo autor, em que há a aproximação dos mercadores com a nobreza pelo fato de seus filhos estudarem juntos 23 .

Ao abordar os manuseios coletivos do impresso, o historiador francês destaca que uma das principais formas de mediação presente no período pré-moderno é a leitura em voz alta que acontece em alguns lugares sociais, tais como oficina ou loja de livros e assembleias religiosas, conferindo o caráter de aprendizagem coletiva desse material. Das formas de apropriação descritas por Chartier, uma em particular nos chama a atenção: os cartazes. Eles, mas principalmente os avulsos e os pasquins, vão representar um importante instrumento de publicização dos conteúdos impressos, publicização essa que vai desaguar nos jornais modernos.

Há outros dois pontos destacados por Chartier sobre práticas de leitura a que vale a pena dar um pouco mais de atenção: o Pasquim e a Biblioteca Azul. Para nós, a formação de uma estratégia discursiva assentada no sensacionalismo presente na contemporaneidade se alicerça, principalmente, sobre esses dois pontos. No caso dos pasquins, é interessante destacarmos, primeiramente, a padronização e a regularidade de suas tiragens, sem, é claro, desprezarmos o fato de que as elites urbanas consumiam o seu conteúdo editorial. Apesar de o autor

22 Chartier, Roger (2004). Leituras e leitores na França do Antigo Regime, São Paulo: Ed. UNESP.

23 Situação análoga é a de Menocchio em $O$ queijo e os vermes, onde Ginzburg mostra como o moleiro se apropriava dos conteúdos discursivos que circulavam no Antigo Regime. 
trabalhar com os primórdios da circulação e do consumo em larga escala de textos impressos, a tentação de comparar com a grande imprensa brasileira é grande, especialmente em função dos temas imersos nas "novidades" trazidas pelos periódicos. Como destaca o autor,

"entre as 517 edições de pasquins (...) seis motivos predominam: os crimes
e as execuções capitais (89 edições), as aparições celestes (86), os feitiços
e possessões diabólicas (62), os milagres (45), as inundações (37), e os
tremores de terra (32)"24.

É interessante observarmos que, em larga medida, já encontramos nos pasquins a presença do sensacionalismo. Para nós, não é outra coisa o que o autor quer dizer quando afirma que o pasquim

\begin{abstract}
"alimenta as imaginações citadinas com narrativas em que o excesso, seja ele o do desregramento moral seja o da desordem dos elementos, e o sobrenatural, miraculoso ou diabólico, rompem com o ordinário do cotidiano"25.
\end{abstract}

Ora, mas não é exatamente desse tipo de material que se alimenta o Daily Reformer de Chesterton?

Nesse processo que buscamos evidenciar parece ter um papel muito especial a Biblioteca Azul. Ela é fundamental para o desenvolvimento das modernas estratégias de narrar em função da tradutibilidade do texto literário e sua massificação. Acompanhando essa massificação do texto literário, outro aspecto bastante interessante é que "desde seus inícios a Biblioteca Azul é, antes de tudo, uma fórmula editorial suscetível de difundir textos de natureza muito diferentes"26. Medicina, astrologia, livros técnicos eram os temas do período pré-moderno; economia, política, internacional, meio ambiente, são os contemporâneos. Tal como acontece no século XXI, esse texto produzido em larga escala, para consumo também em larga escala, mantém o aspecto daqueles editados à época da Biblioteca Azul.

No entanto, há características que marcam os jornais da grande imprensa, que são o caráter individual das leituras, bem como a distinção em possuí-lo e lê-lo.

\footnotetext{
24 Chartier, Roger (2004). Leituras e leitores na França do Antigo Regime, Op. Cit., p. 115.

25 Ibidem.

26 Ibidem, p. 118.
} 
Nesse sentido, o jogo entre produção-distribuição-consumo continua, tornando-se, entretanto, o consumo um poderoso signo de distinção social. Como efeito, o que a Biblioteca Azul introduz com sua estratégia editorial é um sistema de classificação cultural dos produtos, de um lado; e um novo desenho das fronteiras culturais, de outro. No entanto, será a partir de reconfigurações de matrizes da cultura popular na modernidade que o desenho dessas fronteiras se tornará mais evidente, mormente em função do dualismo razão/emoção produzido a partir desse momento histórico.

Ao bipolarizar a cultura a partir do dualismo cultura popular versus cultura erudita ou alta cultura versus baixa cultura, o que o projeto iluminista negligenciou foi o fato de que o popular é ao mesmo tempo o lugar do vulgo e da mediação. No entanto, não podemos deixar de pensar em uma associação do sensacionalismo a uma ideia de democracia, ao incluir o povo no processo de produção da cultura. Ao forjar o dualismo razão/emoção, o projeto iluminista relegou ao segundo o espaço dos excessos, dos sentimentos, das sensações. Mas, ao fazê-lo, conferiu às classes populares um papel importante na dinâmica social. Não sem muito embate, o que as classes altas possibilitaram foi o acesso do povo aos mesmos mecanismos que as permitiam se estabelecer como classe dominante. Barbero27 nos chama a atenção para a presença de uma produção cultural que, sendo destinada ao vulgo, ao povo, não era pura ideologia, já que não só abre às classes populares o acesso à cultura hegemônica, mas confere a essas classes a possibilidade de fazer comunicável sua memória e sua experiência.

A análise de Barbero é fundamental para a compreensão do jogo que se estabelece a partir da modernidade. Se é ilusória a distinção entre alta e baixa cultura, é necessário que se desenvolva uma série de estratégias de conformação do que pertenceria a um campo ou ao outro. É nesse ambiente que o excesso e a contenção emergiram como parâmetros de classificação entre os níveis de cultura. Esse é o contexto em que se associa o melodrama, sobretudo em função do seu caráter excessivo e da sua relação com o carnavalizado, a um gosto estritamente popular.

27 Martín-Barbero, Jesús (2001). Dos meios às mediações: comunicação, cultura e hegemonia, Rio de Janeiro: Editora UFRJ. 
Vejamos algumas características fundamentais do melodrama tomadas a partir de Barbero e de Baltar28: excesso; identificação/projeção (catarse); justiça; dramatização; música; fatalismo; esquematização maniqueísta; hibridização de gêneros; emoticidade (sensações), em oposição à razão; estrutura sintática/gramática própria; presença de mitos, arquétipos, estereótipos, oposição público versus privado; pedagogia moral. O melodrama, pela forma teatral, pela forma dramatúrgica que o compõe no século XIX, vai ser identificado como (a) o espetáculo popular, representando um lugar de chegada de uma memória narrativa e gestual e lugar de emergência de uma cena de massa. Nesse sentido, o melodrama se configura como uma possibilidade concreta de construção de uma memória, de um imaginário.

Já demonstramos em outra oportunidade 29 como o sensacionalismo foi um importante catalisador do processo de circulação do impresso. Nesta ocasião, gostaríamos de focar o conceito de inconsciente político nos termos trabalhados por Fredric Jameson 30 . Sua proposta está associada à ideia de que o romance vai se reconfigurar no século XIX, deixando de ser um gênero "autônomo" para se tornar um gênero atravessado pelas questões de então. Neste autor, tal como acontece com os que trabalhamos até aqui, a presença da circularidade das matrizes é um traço constitutivo do romance moderno. Isso, de alguma forma, coloca Jameson no centro das questões que nos interessam frontalmente. Nele também vamos encontrar a ideia de que, apesar das possibilidades que o "novo" romance oferece, é necessário que as leituras sejam feitas dentro de um universo minimamente compartilhado pelos leitores. Para o autor, "ele [o romance] não se limita a solicitar do leitor que reconstrua essa casa e paisagem por meio de um olhar interior, mas que as reinvente como uma Idéia e como desejo do seu coração"31. Como é o leitor quem valora, quem atribui desejo e sentido à obra, novamente a noção de Protocolos de Leitura se revela uma importante chave na compreensão de por que os leitores, a despeito de serem diferentes uns dos outros, respondem a esses estímulos de forma ou menos parecida.

28 Baltar, Mariana (2006). "Moral deslizante. Releituras da matriz melodramática em três movimentos". Texto apresentado na XV COMPÓS, Bauru (SP).

29 Borges, Wilson Couto (2009). Narrativas jornalísticas como produção material da cultura: a presença do imaginário na construção ideológica em torno da criminalidade, Op. Cit.

30 Jameson, Fredric (1992). O inconsciente político: a narrativa como ato socialmente simbólico, São Paulo: Ática.

31 Ibidem, p. 159. Grifo nosso. 
Uma das possibilidades apresentadas no trabalho de Jameson é que, a partir da formação de um inconsciente político, é possível aos produtores das obras literárias forjarem um discurso mais ou menos semelhante sobre a dinâmica social. Compartilhando dessa perspectiva, nossa investigação tem se desenvolvido no sentido de apontar que essa mesma formação que interfere na produção se espraia para o conjunto da sociedade reconfigurando essa dinâmica. Colocado em outros termos, o que estamos propondo é que, ao universalizar elementos que são em alguma medida particulares aos produtores culturais, os leitores "emprestam" sentido a algo que é particular, mas que recebe o caráter de universal.

Assim, ao explorarmos as pistas oferecidas por Jameson - para quem 0 poeta reproduz seus anseios, seus desejos, a partir da formação de um inconsciente político - gostaríamos de destacar que, num jogo dialético, essa reconfiguração do mundo feito pelo produtor volta para o mundo num processo dinâmico e contínuo. Portanto, nossa proposta é que o inconsciente político compõe não só o corolário que fornece elementos para a produção textual, mas também é aquele que é responsável por uma atribuição de sentidos de forma mais ou menos parecida por um universo de leitores bastante heterogêneo a partir da formação de um imaginário social32.

Uma segunda pista é quanto ao caráter exclusivo desse jogo que se dá no campo estrito da produção literária. Já vimos o quanto a produção discursiva dos periódicos responde, inicialmente, a um alargamento da produção textual e à sua consequente popularização. Uma vez que o jornalista também narra o mundo, conferindo sentidos a ele, nos parece crível pensar na possibilidade de que os "homens de imprensa" também universalizaram, através de estratégias narrativas, sentidos, sensações, emoções que são particulares.

Como extensão das duas primeiras, uma terceira pista diz respeito à relação entre os processos de expansão do mercado editorial e o de civilização. Para nós, eles caminharam vis à vis com a distribuição do ideário iluminista. Evidentemente, não estamos afirmando que o mercado editorial se expandiu por conta do lluminismo, tampouco que este concebeu um processo civilizatório onde a

32 Estamos optando por trabalhar inicialmente com o conceito de imaginário social por entender que, em si, ele compreende tanto o aspecto racional quanto o emocional dos atores sociais. Evidentemente, é a contribuição jamesiana que abre essa perspectiva, uma vez que traz para o debate contemporâneo a possibilidade de as emoções (entendidas por ele a partir do conceito de inconsciente político) atravessarem a atividade produtora de um autor mesmo dentro da racionalidade burguesa. 
impressão fosse essencial. Na verdade, há um fluxo do imaginário que precede a Idade das Luzes e a sucede. Mas, igualmente, não há como negar que esses dois fatores foram importantes para a expansão dos valores burgueses a partir do século XVIII.

Porém, admitindo a presença desse projeto político iluminista, cuja separação entre razão/emoção era (e cremos que continua sendo) fundamental, avaliamos que na contemporaneidade essas características aparecem misturadas, uma vez que são constitutivas dos agentes sociais. É assim que os jornais se revelam espaços privilegiados para percebermos como essa relação entre razão e sensação aparece através das pistas, das marcas, dos sintomas revelados em suas páginas.

IV

Uma das questões mais centrais de nossas investigações diz respeito ao quanto a formação de um imaginário interfere decisivamente na forma como os indivíduos, na contemporaneidade, se apropriam daquilo que ouvem, leem e assistem conferindo-Ihe sentido. Isso porque partimos da premissa de que uma quantidade significativa de narrativas - nos interessam em particular as midiáticas são produzidas a partir de um conjunto de referenciais que tem como marco fundador a passagem do Império à República no Brasil, iluminando o que deve ser lembrado e buscando obstaculizar o que deve ser esquecido.

$\mathrm{Na}$ verdade, não negligenciamos o fato de que se um determinado projeto é colocado em marcha naquele momento histórico ele não é isento de disputas. No entanto, se há ruptura, o que mais evidencia a presença de um projeto burguêsconservador é a continuidade de boa parte dos processos que ali foram gestados. Esse é o sentido de argumentarmos que há uma íntima relação entre os protocolos de leitura associados a tal projeto (com suas devidas atualizações históricas) e que os mesmos influenciam decisivamente na forma como os sujeitos conferem sentido ao antagonismo social.

Em nossa avaliação, há uma estreita relação entre as narrativas dos meios de informação, especialmente pelo apelo que fazem às emoções, aos sentimentos, às sensações, e a construção do imaginário dos indivíduos. A aproximação entre as narrativas jornalísticas e a construção do imaginário se dá justamente em função da 
expansão dos romances de sensação ter acontecido preponderantemente através dos jornalistas, grandes precursores da presença de tais romances nas páginas dos periódicos. Assim, a despeito de ser o leitor quem valora uma leitura, dando sentido a ela, com o romance de sensações espera-se que o conjunto de leitores de uma dada formação social responda aos estímulos produzidos por eles de forma mais ou menos homogênea. Ou seja, podemos perceber o discurso produzido pela mídia a partir de um duplo movimento: de um lado, a presença do verossímil; por outro, um regramento (imaginação regrada) investido no imaginário. Nessa perspectiva, os atores sociais tendem a compreender a realidade - na verdade, uma mistura entre 0 real e o ficcional33 - de forma mais ou menos semelhante em função de um conjunto de convenções que são interiorizadas em seu imaginário.

Nesse processo, é preciso dar destaque à memória e igualmente ao esquecimento como instâncias antitéticas e dialéticas no processo de produção da realidade. Evidentemente, a memória só existe enquanto categoria discursiva, enquanto narrativa, o que traz Ricoeur para o centro desse debate. Mas, a presença do filósofo francês aqui se faz necessária sobretudo em função de sua noção de que a narrativa se revela na tessitura da intriga, uma atividade produtora que se realiza dentro de certas regras culturais. Com essa abordagem, abre-se caminho para a interpretação da ação humana a partir da leitura/compreensão que o significar humano produz, dentro de uma relação dialética e viva entre a prefiguração do mundo (ou mimese I); sua configuração (mimese II) e a reconfiguração (mimese III), ressaltando que é através da mimese II que a mediação entre a apropriação do mundo e a sua reconfiguração acontece.

Da tríplice mimese ricoeuriana, iniciemos com a mimese I. Para Ricoeur,

"a narrativa não se limita a fazer uso de nossa familiaridade com a trama conceitual da ação. Acrescenta a esta os traços discursivos que a distingue de uma simples sequência de frases de ação"34.

É bem verdade que tais traços discursivos são reveladores de um jogo dialético entre aquilo que assumimos que seja a verdade (ainda que ela seja verossímil) e o que pretendemos empreender no mundo. Esse, afinal, é o círculo

33 Para Ricoeur, como os relatos com pretensão de verdade e os relatos ficcionais se embaralham, não apresentando fronteiras fixas, haveria uma unidade ficcional entre modos e gêneros narrativos: 0 tempo. Cf. Ricouer, Paul (1994). Tempo e Narrativa, Campinas: Papirus, Vol. 1.

34 Ibidem, p. 90. 
hermenêutico de que fala o autor, onde a conexão dupla entre regras de tessitura da intriga e termos de ação constitui uma relação de pressuposição e uma de transformação. No entanto, tais narrativas são elaboradas dentro de um conjunto de regras, de convenções, que estabelecem alguns limites à atividade de tecer intrigas. Ou seja, se por um lado temos uma atividade altamente produtora/criativa, por outro temos um controle (uma regulação) dos mecanismos que, em larga medida, condicionam tal atividade.

Em nossa análise, os meios de comunicação de massa têm sido amplificadores deste regramento na medida em que cristalizam determinado uso social da língua, dando forma à ideologia dominante. Ainda que a proposta do autor seja evidenciar o caráter ativo da elaboração da obra no mundo, de um fazer que dê unidade entre a prefiguração e a refiguração, através da configuração (mediação), temos trabalhado com a perspectiva de a regulação/normatização dos códigos culturais servirem à reificação do status quo na justa medida em que limitam as alternativas (principalmente se levarmos em conta a interferência dos meios de comunicação na dinâmica social) de respostas dos indivíduos. O principal esforço das nossas elites (classes dirigentes do projeto civilizador brasileiro) tem sido no sentido de naturalizar os códigos culturais. Se consideramos que os meios de informação têm tido a primazia desse processo, não podemos negligenciar o fato de que se trata de um processo um pouco mais antigo, que pode ser remontado à Idade Média, como propõe Ricoeur, destacando a pertinência do conceito bakhtiniano de circularidade.

Note-se que, na dinâmica acima descrita, os meios de comunicação assumem a centralidade na constituição do sistema de ideias dominantes que têm orientado as ações humanas, evidenciando o que é socialmente importante - que, portanto, deve estar presente na pauta de debates públicos oferecidos pelas narrativas jornalísticas - naquilo que acontece cotidianamente em nossa sociedade.

Nessa perspectiva, ganha relevância o processo de produção de um imaginário social. Imaginário esse que serviria para modelar a recepção, por exemplo, através de protocolos de leitura. Assim, o discurso midiático, a partir de uma construção narrativa onde as sensações, emoções e sentimentos são apelados, valorando a vida e normatizando-a, encontra forte ressonância entre os leitores, ouvintes ou telespectadores. Em nossa avaliação, é justamente na mimese II (que possui a função de mediação) que acontece a aproximação com a construção 
da identidade dos sujeitos sociais. Isso se torna possível à medida que o passado é evocado e, por uma ação produtora, vai retornar ao mundo, refigurando-o. Assim, a tessitura da intriga seria o meio pelo qual o ser humano recebe as ressonâncias do mundo, configura-as e produz leituras, que também retornaram ao mundo.

O papel da articulação da memória (e, consequentemente, do que deve ser esquecido) nesse jogo é central. Como essa memória evocada recebe um investimento dos projetos que a sociedade abraça, é interessante pensarmos o quanto as respostas (ou atos de configuração) são mais ou menos semelhantes do ponto de vista da ação individual. Evidentemente, não estamos buscando apontar uma dicotomia simplificadora entre a ação e o regramento na construção dos nossos argumentos. Porém, não podemos deixar de pensar o quanto essas ações (produtoras, individuais) têm recebido um investimento de longa duração na conformação de uma maneira mais ou menos análoga de agir. Por mais que o sentido se complete na mediação que o homem realiza, não devemos descartar a indução que os protocolos sociais exercem sobre o ato configurante. Se tomarmos como referência a construção da ideia de ordem (e com ela a de desordem, com os sujeitos "desviantes" sendo criminalizados) não é de se estranhar que toda a carga repressiva contra os crimes narrados nas páginas dos jornais encontre eco na sociedade.

Um dos efeitos mais perniciosos desse processo é o fato de as narrativas produzidas pelos meios de comunicação (principalmente na chamada imprensa informativa) receberem a chancela de verdadeiras, como se de fato não fossem discursos produzidos a partir de interesses claramente ideológicos. Evidentemente, tal articulação midiática está imersa num processo complexo onde o lembrar tem tanto ou menos peso que o esquecer, com disputa pelos recursos utilizados para que se rememore.

Como o foco do nosso interesse são os media, não podemos desprezar o tipo de memória com o qual trabalham (o excepcional), tampouco o quanto transformam seus documentos em monumentos, associado ao fato de se investirem de autoridade para apontar e destacar o que deve e como deve ser lembrado. Ao lembrarmos de algo no presente, não devemos perder de vista a necessidade de esquecermos de outras tantas lembranças. No entanto, também não podemos negligenciar o quanto a memória e o que deve ser esquecido se articulam com a 
identidade. Identidade essa que é produzida a partir de um jogo dialético e processual originado de situações, posições, interações.

Mas, deste jogo entre lembrar e esquecer, queremos nos deter sobre dois pontos que nos parecem cruciais para a presente discussão. $O$ primeiro é 0 esquecimento. Mais ainda, o esquecimento como ausência da coisa lembrada, que permite representações. O segundo é a imaginação regrada, que representaria uma suposta eliminação da consciência imaginante, permitindo certa cristalização da "média" das imaginações.

Para tanto, gostaríamos de estabelecer uma aproximação entre Ricoeur e Huyssen 35 a partir da tipologia proposta pelo primeiro para pensar os usos e abusos da memória. As análises desses autores em torno do esquecimento manipulado tornam-se bastante interessantes quando pensadas à luz, por exemplo, da Ditadura brasileira ocorrida entre as décadas de 1960 e 1980. Mesmo depois de produzirem toda sorte de cerceamento e repressão, os militares são convocados para solucionar o problema do conflito urbano na cidade do Rio de Janeiro em pelo menos cinco ocasiões ${ }^{36}$.

Podemos inferir que, no caso brasileiro, a anistia política representou não somente o esquecimento das demandas sociais, representadas pelas reformas de base que 0 presidente João Goulart ameaçava pôr em curso, mas também 0 esquecimento das atrocidades cometidas durante o regime. Cremos que a ação do Exército em 1992 revela esse duplo trabalho de memória (o lembrar e o esquecer). Por um lado, temos o esquecimento 37 produzido a partir do apagamento de um regime que trouxe profundas marcas no cenário nacional brasileiro; por outro, a memória 38 , fomentada pela cobertura jornalística, através de um projeto de recuperação da imagem do Exército que passou por um ostracismo no interregno

\footnotetext{
35 Huyssen, Andréas (2005). "Resistência à memória: os usos e abusos do esquecimento público". In: Bragança, Aníbal e Moreira, Sônia Virginia (org.). Comunicação, acontecimento e memória, São Paulo: Intercom.

36 RIO-92, Rio I e Rio II, Rio contra o crime e, apesar da natureza distinta, o Pan-Rio 2007.

37 Podem-se observar em 1992 os três tipos de abuso de esquecimento proposto por Ricoeur. O impedido, para quem sofreu diretamente com os excessos do regime militar; o manipulado, através das narrativas produzidas pela imprensa; o convocado, primeiro com a própria anistia e posteriormente com a ideologia que vem orientando a questão da segurança pública.

38 De forma análoga ao esquecimento, também os três tipos de memória são produzidos: a memória impedida, quando se apaga (ou melhor, se tenta apagar) o que representou a ditadura; a manipulada, novamente com o trabalho discursivo dos meios de informação; e a convocada, que se revela sobretudo por uma assunção contemporânea de que a ação do Exército (ou das Forças de Segurança) é mais eficaz que a das Polícias Civil e Militar do Rio de Janeiro.
} 
entre o fim da ditadura e a primeira década de 1990. Os exemplos poderiam se multiplicar. Mas, o que queremos ressaltar é o quanto a relação da memória e do esquecimento mantém proximidade com a formação de um imaginário, que interfere na maneira como os indivíduos conferem sentido às narrativas produzidas pelos meios.

Nossa principal linha de investigação se desenvolve em torno da concepção de que houve um deslocamento da luta ideológica para o campo cultural, especialmente em função da centralidade que os veículos de informação passam a ter nos debates políticos contemporâneos. Isso porque, mais que meros difusores da produção material da cultura, os media desempenham um papel preponderante no antagonismo social sobre o qual a sociedade brasileira se construiu.

Ao realizarmos um mapeamento das construções narrativas da imprensa39, pudemos perceber e apontar as relações existentes (no plano do discurso) entre uma "criminalidade sempre crescente" e a necessidade de aumento da repressão, (materializada na "intervenção das Forças Armadas") no Rio de Janeiro. Com essa perspectiva, buscamos evidenciar o deslocamento do conflito entre classes para dentro do espaço publidiático, identificando os sinais que podem nos revelar que este espaço se constitui como um lugar privilegiado para assistirmos àquilo que Zizek definiu como "presença da ideologia justamente no lugar onde se julga que ela não esteja"40.

Ao trabalhamos com a premissa de a imprensa, a partir da veiculação de um discurso próprio, interferir decisivamente no jogo de disputas entre as classes, é porque entendemos que a produção discursiva gerada por ela acerca do antagonismo social produz, como um dos seus efeitos, a construção/reificação de um imaginário social que orienta as ações engendradas por outros atores sociais. Se voltarmos ao episódio com o qual abrimos este artigo, poderemos perceber o quanto a construção narrativa gerada pelo repórter evidencia o fato de que medidas letais contra marginais são aceitáveis. Ora, a palavra marginais, no sentido tomado por

39 Borges, Wilson Couto (2009). Narrativas jornalísticas como produção material da cultura: a presença do imaginário na construção ideológica em torno da criminalidade, Op. Cit.

40 Zizek, Slavoj (1996). Um Mapa da Ideologia, Rio de Janeiro: Contraponto. 
aquele ator e difundido nas ondas do rádio, acaba por abarcar tanto aqueles que vivem à margem quanto na margem. Tomando por base a ideia de que as informações jornalísticas são, em larguíssima medida, assumidas pelo senso comum, e que o sentido que aquela expressão assume fortalece o desrespeito aos direitos humanos, fica muito evidenciado que os excessos produzidos contra os considerados perigosos devem ser tolerados. Esse tipo de construção semântica revela, dentre outros aspectos, o lugar de produção e enquadramento da memória coletiva - sem que nos esqueçamos do esquecimento igualmente produzido - que converte a imprensa, não naquele partido orgânico do qual Gramsci já abordou, mas na sociedade civil, na medida em que pasteuriza os discursos sociais dentro dela.

É por isso que faz todo o sentido pensar a imprensa (não aquela habermasiana que iluminava a esfera pública, mas como se a própria esfera pública fosse) como o "Poder Moderador" de que tratou Albuquerque ${ }^{41}$, entendendo-a em sua dimensão política, uma dimensão que mascara que as interpretações produzidas pelos meios representam um lugar de interpretação da realidade, mas não o único. Note-se que, antes das transformações por que passaram algumas empresas jornalísticas (anos 1950-60) não havia distinção entre as chamadas imprensa informativa e imprensa sensacionalista. Isto significa dizer que a adaptação da realidade brasileira aos parâmetros norte-americanos produziu a noção de que se tratava da distinção entre um jornalismo independente, principalmente de ligações políticas, e um outro que representava claramente vinculações com interesses político-ideológicos. Mas, uma vez que se trata de realidades distintas, com contextos culturais igualmente distintos, talvez faça mais sentido pensar, concordando com o autor, que os homens da imprensa se atribuam o papel de solucionar conflitos na nossa sociedade.

Ainda que Albuquerque destaque que o Poder Moderador fosse "a solução clássica, da Constituição de 1824, acrescentando aos três poderes originais um quarto, o Poder Moderador, exercido pelo Imperador e encarregado de resolver conflitos entre o Executivo e o Legislativo"42 e que fosse uma estratégia criada "sob medida para os interesses de Pedro I, tal arranjo político demonstrou ter um

\footnotetext{
41 Albuquerque, Afonso de (2000). “Um outro 'Quarto Poder': imprensa e compromisso político no Brasil". In: Contracampo: Revista do Mestrado em Comunicação, Imagem e Informação, no 4, p. 2357.

42 Ibidem, p. 29-30.
} 
invejável fôlego, resistindo até a proclamação da República, em 1889"43 - sendo atribuído tal poder aos militares, posteriormente ${ }^{44}$-, inferimos se uma certa fantasia mediadora (moderadora) já não atravessa as mentes dos homens de imprensa (que em muitos dos casos eram também homens das letras).

Afinal, não nos parece fortuito o debate fomentado pelo plebiscito sobre 0 sistema de governo (1993) trazer a "necessidade" da existência "do poder moderador do rei"45, mesmo após 104 anos de República. A presença dessa proposta, mesmo um século após o fim do Império, nos parece reveladora do quanto a formação de um imaginário atua na ação humana. Menos fortuita ainda parece ser a noção de perfeição subsumida na moderação evocada - a de um monarca caracterizada pela possibilidade de determinar, de maneira "isenta", quais são as melhores alternativas para a sociedade.

Quando apontamos a primazia da imprensa no processo de construção de uma dada ordem social, destacando a presença do sensacionalismo e a importância que a construção de um imaginário tem na forma como os sujeitos sociais se apropriam das informações produzidas pelos meios, julgamos que nos aproximamos de análises como as de Ginzburg, especialmente em função de sua afirmação de que

"o mesmo paradigma indiciário usado para elaborar formas de controle social (...) pode se converter num instrumento pra dissolver as névoas da ideologia que obscurecem a estrutura social como a do capitalismo maduro (...). Se a realidade é opaca, existem zonas privilegiadas - sinais, indícios que permitem decifrá-las,46.

Obviamente, o que a formulação da proposta do historiador italiano indica é que a construção desse imaginário social se estabelece num processo que é de longuíssima duração. Se olharmos para as construções narrativas produzidas pela imprensa caindo naquela cilada de que se trata da descrição de fatos episódicos e cotidianos, perderemos a dimensão do quanto o processo de construção da ordem burguesa remete a momentos históricos não visíveis ao primeiro olhar.

\footnotetext{
43 Ibidem.

44 Albuquerque explica que às Forças Armadas foi associado o papel de um poder neutro, apolítico, responsável pelo equilíbrio entre os três poderes e a ordem pública. Essa lógica foi rompida em 1964 quando a linha-dura dos militares tomou o poder, mantendo-se nele até o primeiro quinquênio dos anos 1980 .

45 Albuquerque, Afonso de (2000). Op. Cit., p. 29-30.

46 Ginzburg, Carlo (1989). Mitos, Emblemas e Sinais, São Paulo: Cia. das Letras, p. 177.
} 
No horizonte das nossas observações está a perspectiva de que há compromissos longevos que ainda atravessam o imaginário da formação social brasileira na passagem do século XX ao XXI. Quando nos recordamos da "via prussiana" de desenvolvimento da sociedade brasileira, como destacou Cerqueira Filho, podemos perceber 0 quanto ela pode ser concebida como "metáfora/metonímia para um complexo de afetos, emoções e sentimentos inconscientes (...) que obstaculizam a prática política liberal e democrática ainda hoje no Brasil"47.

Ao fazer referência aos afetos e sentimentos inconscientes, o autor se aproxima da investigação proposta por Barbero sobre a pesquisa na América Latina nos anos 1990. No entanto, nos parece infrutífero olhar para o final do século $X X$ sem lançar os olhos para seu início, isto porque seria lá que poderíamos encontrar alguns contornos daquilo que assistimos contemporaneamente, mormente no que diz respeito aos meios de informação. Com esse olhar, torna-se muito pertinente a incorporação de Nicolau Sevcenko no desenvolvimento da nossa reflexão, especialmente no que ele nos diz sobre o exercício intelectual como atitude política, imerso na construção do regime republicano brasileiro. No entanto, queremos reter deste autor aquilo que aparece em sua obra como um dado marginal.

Não nos parece um mero apêndice a presença de "campanhas na imprensa" sobre o modelo de sociedade que se erigia no Brasil no início do século XX. Não queremos vilipendiar as contribuições do autor, principalmente porque não perdemos de vista que seu objeto de estudo era outro. Entretanto, a pouca importância dada à imprensa em detrimento dos literatos obliterou um pouco, acreditamos, o papel dos meios no processo de formação social brasileiro 48 . Isso porque, se de fato os literatos tiveram um papel importante na construção dessa ordem burguesa (e a proliferação dos romances de sensação é um indicativo disso), (a) não foi através deles que se irradiava para o restante do país aquele conjunto de

47 Cerqueira Filho, Gisálio (2005). Autoritarismo afetivo: a Prússia como sentimento, São Paulo: Escuta, p. 30.

48 Poderíamos até tentar entender que o período trabalhado pelo historiador não contava com os jornais organizados como empresa jornalística, o que poderia sugerir que não contávamos com uma classe organizada em termos profissionais, ou com o prestígio social, como os literatos. Mas, é justamente por entender que a ação dos homens de imprensa já se fazia sentir com muita ênfase na passagem do século XIX para o XX e que as décadas de 1930 e 1960 não mudaram substancialmente (ou seja, na forma) a estrutura narrativa dos relatos do dia a dia que optamos por evidenciar que naquele momento histórico os marcos para a ação moderadora dos meios já começavam a florescer. 
transformações - não podemos esquecer, tampouco o faz o autor, do contingente bastante significativo de iletrados espalhados (aproximadamente 86\% da população) não só no Distrito Federal, mas por todo o território nacional - e (b) era na imprensa que referidas campanhas ganhavam a sociedade - o que muito provavelmente era corroborado pelo fato de as técnicas de oralidade permitirem uma circularidade muito maior do que a escrita 49 .

Temos a exata noção de que a imprensa não julga (do ponto de vista legal) os comportamentos desviantes na nossa sociedade. Antes, porém, não é menos verdade que ela julgue moralmente, antecipando, em muitíssimos casos, a condenação pública daqueles que divergem dos modelos hegemonicamente celebrados - como, por exemplo, legitimando o extermínio dos "marginais". Assim, nos interrogamos: na contemporaneidade, quando se elimina dos debates publidiáticos as alternativas para a politização da "questão social", não se está simultaneamente produzindo a inscrição de que não há alternativas? Ou, propondo em outros termos, quando se dá voz a determinadas construções, deixando de fora as que a essas se opõem, não se estaria concomitantemente produzindo o que deve (e o que não vai) ser celebrado? É por isso que o estudo das narrativas jornalísticas é central, porque ao interferir na produção material da cultura, eliminando de suas páginas as tensões que atravessam qualquer modelagem social, o que os meios fomentam é a formação de mentalidades (ou de imaginações) acerca do antagonismo social. Nesse sentido, o que as informações noticiosas produzem é uma espécie de soberania sobre as imaginações ou, mais especificamente, uma hegemonia ideológica atravessada pela questão do imaginário.

\section{Referências Bibliográficas}

Albuquerque, Afonso de (2000). “Um outro 'Quarto Poder': imprensa e compromisso político no Brasil”. In: Contracampo: Revista do Mestrado em Comunicação, Imagem e Informação, nº 4, p. 23-57.

\footnotetext{
49 O próprio Sevcenko destaca que as tiragens dos jornais excediam em mais de mil por cento às dos livros e que os que liam nas capitais limitavam-se aos jornais. Ainda que admita que os números não refletiam a quantidade de leitores, nos parece um indício bastante evidente de que, se havia difusão das ideias, ela era fomentada pelos periódicos e não pela literatura. Para mais detalhes ver Sevcenko, Nicolau (1989). Literatura como missão: tensões sociais e criação cultural na Primeira República, Op. Cit. ou ainda Barbosa, Marialva (2007). História Cultural da Imprensa: Brasil, 1900 2000, Rio de Janeiro: Mauad X.
} 
Baltar, Mariana (2006). "Moral deslizante. Releituras da matriz melodramática em três movimentos". Texto apresentado na XV COMPÓS, Bauru (SP).

Barbosa, Marialva (2007). História Cultural da Imprensa: Brasil, 1900-2000, Rio de Janeiro: Mauad X.

Barbosa, Marialva e Enne, Ana Lucia S (2006). "O jornalismo popular, a construção narrativa e o fluxo do sensacional". Artigo apresentado na LUSOCOM/2006, Santiago de Compostela/Espanha.

Borges, Wilson Couto (2009). Narrativas jornalísticas como produção material da cultura: a presença do imaginário na construção ideológica em torno da criminalidade, Niterói: Tese de Doutorado em Comunicação, UFF.

(2006). Criminalidade no Rio de Janeiro: a imprensa e a (in)formação da realidade. Rio de Janeiro: Revan.

Carvalho, José Murilo (1990). A formação das almas: o imaginário da República no Brasil, São Paulo: Cia. das Letras.

Castoriadis, Cornélius (1987). A instituição imaginária da sociedade, Rio de Janeiro: Paz e Terra.

Cerqueira Filho, Gisálio (2005). Autoritarismo afetivo: a Prússia como sentimento, São Paulo: Escuta.

Chartier, Roger (2004). Leituras e leitores na França do Antigo Regime, São Paulo: Ed. UNESP.

(1996). Práticas de leitura, São Paulo: Estação Liberdade.

Chesterton, G. K. (2004). "A cabeleira roxa". In: Braga, R. (Coord.). Contos ingleses, Rio de Janeiro: Ediouro. 
Ginzburg, Carlo (2002). História noturna. Decifrando o Sabá, São Paulo: Cia. das Letras.

Ginzburg, Carlo (1989). Mitos, Emblemas e Sinais, São Paulo: Cia. das Letras.

Habermas, Jürgen (1984). Mudança estrutural da esfera pública, Rio de Janeiro: Tempo Brasileiro.

Huyssen, Andréas (2005). "Resistência à memória: os usos e abusos do esquecimento público". In: Bragança, Aníbal e Moreira, Sônia Virginia (org.). Comunicação, acontecimento e memória, São Paulo: Intercom.

Jameson, Fredric (1992). O inconsciente político: a narrativa como ato socialmente simbólico, São Paulo: Ática.

Martín-Barbero, Jesús (2004). Ofício do Cartógrafo, São Paulo: Loyola.

(2001). Dos meios às mediações: comunicação, cultura e hegemonia, Rio de Janeiro: Editora UFRJ.

Ricouer, Paul (2003). La memoria, La historia, El olvido, Madri: Trotta. (1994). Tempo e Narrativa, Campinas: Papirus, Vol. 1.

Sevcenko, Nicolau. (1998) (org.). História da vida privada no Brasil, vol. 3 República: da Belle Époque à era do rádio, São Paulo: Cia. das Letras.

(1989). Literatura como missão: tensões sociais e criação cultural na Primeira República, São Paulo: Brasiliense.

Véron, Eliseo (1981). A produção de sentido, São Paulo: Cultrix. 
Zizek, Slavoj (1996). Um Mapa da Ideologia, Rio de Janeiro: Contraponto. 